\title{
Surpass Flow Diverter in the Treatment of Intracranial Aneurysms: A Prospective Multicenter Study
}

\author{
A.K. Wakhloo, P. Lylyk, J. de Vries, C. Taschner, J. Lundquist, A. Biondi, M. Hartmann, I. Szikora, L. Pierot, N. Sakai, H. Imamura, \\ N. Sourour, I. Rennie, M. Skalej, O. Beuing, A. Bonafé, F. Mery, F. Turjman, P. Brouwer, E. Boccardi, L. Valvassori, S. Derakhshani, \\ M.W. Litzenberg, and M.J. Gounis, for the Surpass Study Group
}

\begin{abstract}
BACKGROUND AND PURPOSE: Incomplete occlusion and recanalization of large and wide-neck brain aneurysms treated by endovascular therapy remains a challenge. We present preliminary clinical and angiographic results of an experimentally optimized Surpass flow diverter for treatment of intracranial aneurysms in a prospective, multicenter, nonrandomized, single-arm study.
\end{abstract}

MATERIALS AND METHODS: At 24 centers, 165 patients with 190 intracranial aneurysms of the anterior and posterior circulations were enrolled. The primary efficacy end point was the percentage of intracranial aneurysms with $100 \%$ occlusion on 6-month DSA. The primary safety end point was neurologic death and any stroke through a minimum follow-up of 6 months.

RESULTS: Successful flow-diverter delivery was achieved in 161 patients with 186 aneurysms (98\%); the mean number of devices used per aneurysm was 1.05. Clinical follow-up (median, 6 months) of 150 patients (93.2\%), showed that the primary safety end point occurred in 18 subjects. Permanent neurologic morbidity and mortality were $6 \%$ and $2.7 \%$, respectively. Morbidity occurred in $4 \%$ and $7.4 \%$ of patients treated for aneurysms of the anterior and posterior circulation, respectively. Neurologic death during follow-up was observed in $1.6 \%$ and $7.4 \%$ of patients with treated intracranial aneurysms of the anterior and posterior circulation, respectively. Ischemic stroke at $\leq 30$ days, $\mathrm{SAH}$ at $\leq 7$ days, and intraparenchymal hemorrhage at $\leq 7$ days were encountered in $3.7 \%, 2.5 \%$, and $2.5 \%$ of subjects, respectively. No disabling ischemic strokes at $>30$ days or $\mathrm{SAH}$ at $>7$ days occurred. New or worsening cranial nerve deficit was observed in $2.7 \%$. Follow-up angiography available in 158 (86.8\%) intracranial aneurysms showed $100 \%$ occlusion in $75 \%$.

CONCLUSIONS: Clinical outcomes of the Surpass flow diverter in the treatment of intracranial aneurysms show a safety profile that is comparable with that of stent-assisted coil embolization. Angiographic results showed a high rate of intracranial aneurysm occlusion.

ABBREVIATIONS: EVT = endovascular treatment; FD = flow diverter; PUFS = Pipeline Embolization Device for Uncoilable or Failed Aneurysms

$P$ revious in vivo and in vitro hemodynamic experimental studies showed that optimization is required to balance the porosity (metal-free/metal area) and pore or mesh density (number of

Received April 9, 2014; accepted after revision June 25

From the Division of Neuroimaging and Intervention (A.K.W.), Departments of Radiology, Neurology, and Neurosurgery, and New England Center for Stroke Research (M.J.G.), University of Massachusetts Medical School, Worcester, Massachusetts; Department of Neurosurgery (P.L., J.L.), ENERI, Buenos Aires, Argentina; Department of Neurosurgery (J.d.V.), Radboud University Nijmegen Medical Center, Nijmegen, the Netherlands; Department of Neuroradiology (C.T.), University of Freiburg, Freiburg, Germany; Department of Neuroradiology and Endovascular Therapy (A. Biondi), University of Besançon, Besançon, France; Department of Neuroradiology (M.H.), Helios Hospital, Berlin, Germany; National Institute of Neurosciences (I.S.), Budapest, Hungary; Department of Neuroradiology (L.P.), Hôpital Maison Blanche, University Hospital of Reims, Reims, France; Department of Neurosurgery (N. Sakai, H.I.), Kobe City Medical Center General Hospital, Kobe, Japan; Department of Neuroradiology (N. Sourour), Hôpital Pitié-Salpetrière, Paris, France; Department of Neuroradiology (I.R.), The Royal Hospitals, Belfast, Ireland; Department of Neuroradiology (M.S., O.B.), Universitätsklinikum Magdeburg, Magdeburg, Germany; Department of Neuroradiology (A. Bonafé), Hôpital Guy de Chauillac, Montpellier, France; Department of Neurosurgery (F.M.), Pontificia Universidad Católica de Chile, Santiago, Chile; Department of Neuroradiology (F.T.), Hôpital Neurologique, Lyon, France; Department of Neuroradiology (P.B.), Erasmus pores $/ \mathrm{mm}^{2}$ ) of flow diverters (FDs) to optimize the effect on flow reduction within the aneurysm sac while keeping the side branches (perforators) patent. ${ }^{1-6} \mathrm{We}$ evaluated, in a multicenter, prospective, nonrandomized study, our hypothesis that a single optimized FD would suffice to obliterate a variety of aneurysms located in the anterior and posterior circulation without occluding perforators.

\section{MATERIALS AND METHODS \\ Patients and Study Design}

Patients with intracranial aneurysms undergoing attempted endovascular treatment (EVT) with the FD (Surpass FD; Stryker

University Medical Center, Rotterdam, the Netherlands; Department of Neuroradiology (E.B., L.V.), Niguarda Ca' Granda Hospital, Milan, Italy; Department of Neuroradiology (S.D.), Essex Center for Neurological Sciences, Queen's University Hospital, London, United Kingdom; and Stryker Neurovascular (M.W.L.), Fremont, California.

Please address correspondence to Ajay K. Wakhloo, MD, PhD, FAHA, Division of Neuroimaging and Intervention H1-144, Departments of Radiology, Neurology, and Neurosurgery, 55 Lake Ave North, University of Massachusetts Medical School, Worcester, MA 01655; e-mail: ajay.wakhloo@umassmemorial.org

Evidence-Based Medicine Level 2.

http://dx.doi.org/10.3174/ajnr.A4078 
Neurovascular, Fremont, California) were enrolled consecutively in a multicenter, prospective data base that included 24 centers in Europe, South America, and Japan. In Europe and Chile, patients were treated with the FD after it received approval for distribution by the Notified Body (CE Mark); outside Europe, patients were treated under a compassionate use protocol. All procedures and the sharing of data recorded in the data base were approved by the institutional review board or ethics committee at each participating site; written informed consent was obtained from all patients or their proxy before the procedure.

Patients were considered for enrollment if they had aneurysms of any size located in the anterior or posterior circulation deemed difficult to treat with currently available surgical or endovascular techniques or expected to have a high recanalization rate with standard EVT (wide-neck defined as $>4 \mathrm{~mm}$ or dome-to-neck ratio of $\leq 2$ ). Patients were not eligible for enrollment if they had experienced a subarachnoid hemorrhage associated with a ruptured intracranial aneurysm within 30 days, had contraindications for dual antiplatelet therapy or were nonresponders to acetylsalicylic acid and clopidogrel, or had a nontreated brain arteriovenous malformation in the territory of the target aneurysm. Inhibition of platelet function was assessed (VerifyNow P2Y12 assay; Accumetrics, San Diego, California), and inhibition between $30 \%$ and $90 \%$ was considered therapeutic. Patients were given acetylsalicylic acid $(81 \mathrm{mg})$ and clopidogrel $(75 \mathrm{mg})$ for a minimum of 3 days before the procedure. Dual antiplatelet therapy was continued for a minimum of 3 months, followed by lifelong continuation of acetylsalicylic acid. A loading dose of $350 \mathrm{mg}$ of acetylsalicylic acid and $150 \mathrm{mg}$ of clopidogrel was given 6-24 hours before EVT if patients were acutely treated. The goal, whenever feasible, was to treat the target vessel with a single device.

Follow-up digital subtraction angiography was typically scheduled at 1-3, 6, and 12 months and, in a few patients, at a later time point, performed on an outpatient basis. All angiograms were evaluated by 2 independent reviewers not involved in patient care. The efficacy end point was the percentage of subjects with $100 \%$ occlusion of the aneurysm.

The safety end point was the percentage of patients experiencing death and any stroke through the minimum follow-up of 6 months. Functional outcome by using the modified Rankin Scale score and cranial nerve II-VI examination was assessed at baseline, at discharge, and at follow-up.

\section{Technology and Endovascular Procedure}

The FD is made of a cobalt-chromium alloy with a low porosity (metal surface area coverage, 30\%); a high mesh density (20-32 pores $/ \mathrm{mm}^{2}$ ); and a self-expanding, single-layer braided, tubular structure. The device comes in various diameters, $\leq 5.3 \mathrm{~mm}$, and lengths, $\leq 50 \mathrm{~mm}$. The $2-\mathrm{mm}$ device has 48 wires; the 3 - and 4-mm devices have 72 wires, and the $5-\mathrm{mm}$ device has 96 wires, to provide a constant high mesh density over various diameters of the device, as supported by previous in vitro ${ }^{5}$ and in vivo studies. ${ }^{6}$ The filament diameter ranges from 25 to $36 \mu \mathrm{m}$, depending on the device diameter, to maintain the mechanical stability of the implant and the square shape of the mesh and the mesh attenuation at the implantation site. The braid angle is designed to avoid changes of mesh density in curved arterial segments and in vary- ing arterial diameters. It also helps to reduce foreshortening of the FD (29\%-42\% depending on implant diameter) from constraint stage to nominal diameter once implanted. To improve radioopacity, the device has 12 platinum wires ( $92 \%$ platinum, $8 \%$ tungsten) integrated in the mesh with the same wire diameter as the remaining cobalt-chromium wires.

The delivery system of the FD is composed of an inner catheter (the pusher) and an outer catheter (the delivery catheter) compatible with any 0.014 -inch microwire. The outer diameter of the distal part measures 3.7F, and of the proximal part, 3.9F. The FD comes premounted at the very distal end of its delivery system. Two different generations of FD delivery systems were used in this study. The system used in the first 45 subjects was stiffer, while the second generation of delivery system had an improved trackability.

Except in 4 patients, the implantation was performed with the patient under general anesthesia. Following access, the patients were administered heparin to maintain an activated clotting time of $>250$ seconds. Typically, a bi- or a triaxial approach was used. A long sheath was placed in either the common carotid or subclavian artery. A guide (intermediate) catheter was navigated through the sheath over either the FD delivery system and a 0.014inch microwire or a standard microcatheter. If a microcatheter was used, an exchange-length 0.014 -inch microwire was introduced and the microcatheter was replaced by the FD delivery catheter. The delivery system has markers indicating the location of the constrained implant and was positioned at the desired site across the aneurysm neck. If satisfactory initial wall apposition was not obtained, postdilation of the FD with a compliant balloon was permitted. Postdilation was performed with compliant balloons, either Scepter C (MicroVention, Tustin, California) or HyperForm (Covidien, Irvine, California). Technical success was defined as the proportion of patients in whom the FD was delivered to cover the aneurysm neck.

\section{RESULTS}

From April 2010 to January 2013, EVT with the FD was attempted in 165 patients with 190 intracranial aneurysms. Single-center results from a small subset of these patients $(n=26)$ have previously been reported. ${ }^{7}$ Patient demographics, clinical presentation at treatment, and indication for EVT are presented in Table 1. Patients with ruptured aneurysms (3.9\%) were treated after initial partial coiling and in a subacute stage at least 30 days following the SAH. Most aneurysms were discovered incidentally or after work-up for chronic headaches (31.8\%). A common reason for the use of the FD was recanalization or regrowth of previously coiled (with or without stent assistance) aneurysms, necessitating re-intervention $(21.7 \%)$. In nearly one-fifth of the aneurysms, mass effect was present with cranial nerve deficits.

Aneurysm characteristics are provided in Table 1. In the anterior circulation, 118 aneurysms $(63.4 \%)$ originated below the internal carotid artery terminus (Fig 1), and 41 (22\%), distal to the circle of Willis (including the middle cerebral artery bifurcation, Fig 2); 27 (14.5\%) originated at various locations in the posterior circulation, including 4 fusiform aneurysms of the entire basilar trunk (Fig 3). The mean aneurysm and neck diameters were $10.4 \pm 0.7$ and $6.0 \pm 0.4 \mathrm{~mm}$, respectively; the dome-to-neck ratio 
Table 1: Patient information and characteristics of aneurysms treated with the FD

\begin{tabular}{|c|c|}
\hline Patients & 161 \\
\hline Aneurysms & 186 \\
\hline Women (\%) & 72.4 \\
\hline Mean age (yr) (range) & $57.1(28-82)$ \\
\hline \multicolumn{2}{|l|}{ Presentation/indications for treatment (\%) } \\
\hline Incidental finding/headaches & 31.8 \\
\hline Recurrent after coiling/coiling and stenting & 21.7 \\
\hline Cranial nerve deficit/mass effect & 18.6 \\
\hline Associated second ruptured aneurysm & 13.1 \\
\hline Stroke/transient ischemic attack & 7.8 \\
\hline Subarachnoid hemorrhage (not acute) & 3.9 \\
\hline Recurrent after clipping/failed clipping & 2.3 \\
\hline Seizures & 0.8 \\
\hline Total No. of aneurysms treated & 186 \\
\hline$<5 \mathrm{~mm}$ & 53 \\
\hline $5-9.9 \mathrm{~mm}$ & 64 \\
\hline $10-20 \mathrm{~mm}$ & 47 \\
\hline$>20 \mathrm{~mm}$ & 22 \\
\hline \multicolumn{2}{|l|}{ Measurements (mean \pm SEM) } \\
\hline Aneurysm dome size (mm) & $10.4 \pm 0.7$ \\
\hline Aneurysm neck size (mm) & $6 \pm 0.4$ \\
\hline Dome: neck ratio & $1.6 \pm 0.08$ \\
\hline Proximal parent artery diameter (mm) & $3.8 \pm 0.1$ \\
\hline Distal parent artery diameter $(\mathrm{mm})$ & $3.0 \pm 0.1$ \\
\hline Anterior circulation ICA (\%) & $118(63.4)$ \\
\hline Petrocavernous & $5(2.7)$ \\
\hline Cavernous & 20 (10.7) \\
\hline Carotid cave & $3(1.6)$ \\
\hline Superior hypophyseal & $5(2.7)$ \\
\hline Paraophthalmic & $34(18.2)$ \\
\hline Paraclinoid ICA & $4(2.2)$ \\
\hline Supraclinoid ICA & $6(3.2)$ \\
\hline Posterior communicating artery & $36(19.4)$ \\
\hline Anterior choroidal artery & $5(2.7)^{\prime}$ \\
\hline Anterior circulation distal to circle of Willis (\%) & $41(22)$ \\
\hline ICA terminus & $5(2.7)$ \\
\hline $\begin{array}{l}\text { Anterior cerebral artery (including AcomA and } \\
\text { pericallosal) }\end{array}$ & $12(6.4)$ \\
\hline Middle cerebral artery & $24(12.9)$ \\
\hline Posterior circulation (\%) & $27(14.5)$ \\
\hline Vertebral artery (VA and VB junction) & $8(4.3)$ \\
\hline Posterior inferior cerebellar artery & $6(3.2)$ \\
\hline Basilar trunk & $9(4.8)$ \\
\hline Posterior cerebral artery & $3(1.6)$ \\
\hline Superior cerebellar artery & $1(0.5)$ \\
\hline \multicolumn{2}{|l|}{ Morphology (\%) } \\
\hline Wide-neck saccular & $125(67.2)$ \\
\hline Fusiform/dissecting & $54(29.0)$ \\
\hline Blister & $7(3.8)$ \\
\hline Focal disease & $100(53.8)$ \\
\hline Dysplastic artery & $86(46.2)$ \\
\hline
\end{tabular}

Note:-AcomA indicates anterior communicating artery; VA, vertebral artery; VB, vertebrobasilar; SEM, standard error of the mean.

was $1.6 \pm 0.08 \%$. Eighty-six aneurysms $(46.2 \%)$ were associated with dysplastic parent arteries, 54 (29\%) were either fusiform or dissecting, and 7 (3.8\%) were blood blister-type. The mean proximal artery diameter was $3.8 \pm 0.1 \mathrm{~mm}$, and the distal parent artery diameter, $3.0 \pm 0.1 \mathrm{~mm}$.

\section{Technical Complications}

Of 190 intracranial aneurysms in which treatment was attempted in 165 patients, access to the target site failed in 4 subjects due to the stiffer first generation of the FD delivery system and the tor- tuosity of the parent artery. Thus, FD placement was achieved in 186 aneurysms (device success of 98\%) or 161 patients (Table 2). The average number of FDs used was 1.05 per aneurysm and 1.2 per patient. Most aneurysms were treated with a single FD (1 device, 127 aneurysms). In 23 and 2 aneurysms, 2 and 3 devices, respectively, were deployed. In 14 and 2 patients with 2 and 3 adjacent aneurysms, respectively, a single FD was used. Additional coils were present from previous treatment or placed in 36 aneurysms (19.3\%). During treatment, imprecise FD placement resulted in incomplete neck coverage in $4(2.1 \%)$ aneurysms (technical success of 97\%) and a guidewire perforation in 5 patients (3.1\%). Guidewire perforation led to SAH and intraparenchymal hemorrhage in 3 and 2 patients, respectively (Table 2). Postdilation of the FD because of a malapposition was performed with compliant balloons in 36 aneurysms (19.4\%). Clot formation on the implant surface was observed in 6 patients (3.7\%), all of which were successfully treated with intra-arterial administration of abciximab (5-18 $\mathrm{mg}$ ) in 4 patients or eptifibatide in 2 subjects. Vasospasm due to catheter manipulation was reported at the tip of or around the long sheath of the guide catheter in 6 patients but promptly resolved with local intra-arterial administration of nicardipine $(n=5,2-15 \mathrm{mg})$ or verapamil $(n=1,10$ $\mathrm{mg}$ ). Periprocedural ICA dissections were reported in 2 patients and led to complete vessel occlusion that remained asymptomatic due to existing collateral blood supply.

\section{Safety and Clinical Outcome}

During the clinical follow-up (median, 6 months; range, 1-38 months) available in 150 (93.2\%) patients, a primary end point occurred in 18 subjects (12\%). Of these patients, 5 (3.3\%) returned to baseline during follow-up, $5(3.3 \%)$ continued to experience a minor neurologic deficit ( $\mathrm{mRS} \leq 2), 4$ (2.7\%) have permanent major neurologic disabilities ( $m R S>2$ ), and $4(2.7 \%)$ died. Of the patients with a primary end point, hemorrhage was seen in 10 patients $(6.2 \%)$ and was related to the following: 1 ) a periprocedural wire perforation in $5(3.1 \%)$ patients, 2) a subdural hematoma that developed within 24 hours in 1 patient who was kept on therapeutic heparin and required surgical decompression, 3) a subarachnoid hemorrhage 5 days after implant in 1 subject, and 4) intraparenchymal hemorrhage seen in 3 patients following FD implantation and up to 14 days following EVT. No further aneurysmal ruptures were encountered during the follow-up period. New or worsening of pre-existing cranial nerve deficits following treatment were observed in $4(2.7 \%)$ subjects. There were an additional 3 deaths during the follow-up period from nonvascular causes: One patient was diagnosed with lung cancer 1 year following aneurysm treatment and died 1 year thereafter, 1 was lost to follow-up and was subsequently discovered to have died from complications of a brain tumor, and 1 patient died from pneumonia 1 year after FD implantation. Changes in the $\mathrm{mRS}$ score are reported in Fig 4.

Anterior Circulation. In the subgroup analysis, 5 patients with anterior circulation aneurysms experienced permanent neurologic deficits and 2 patients died. Complications were related to thromboembolic events in 3 patients, including 1 patient with a 16-mm ophthalmic artery aneurysm who had a delayed anterior choroidal artery occlusion and a stroke following the procedure. 

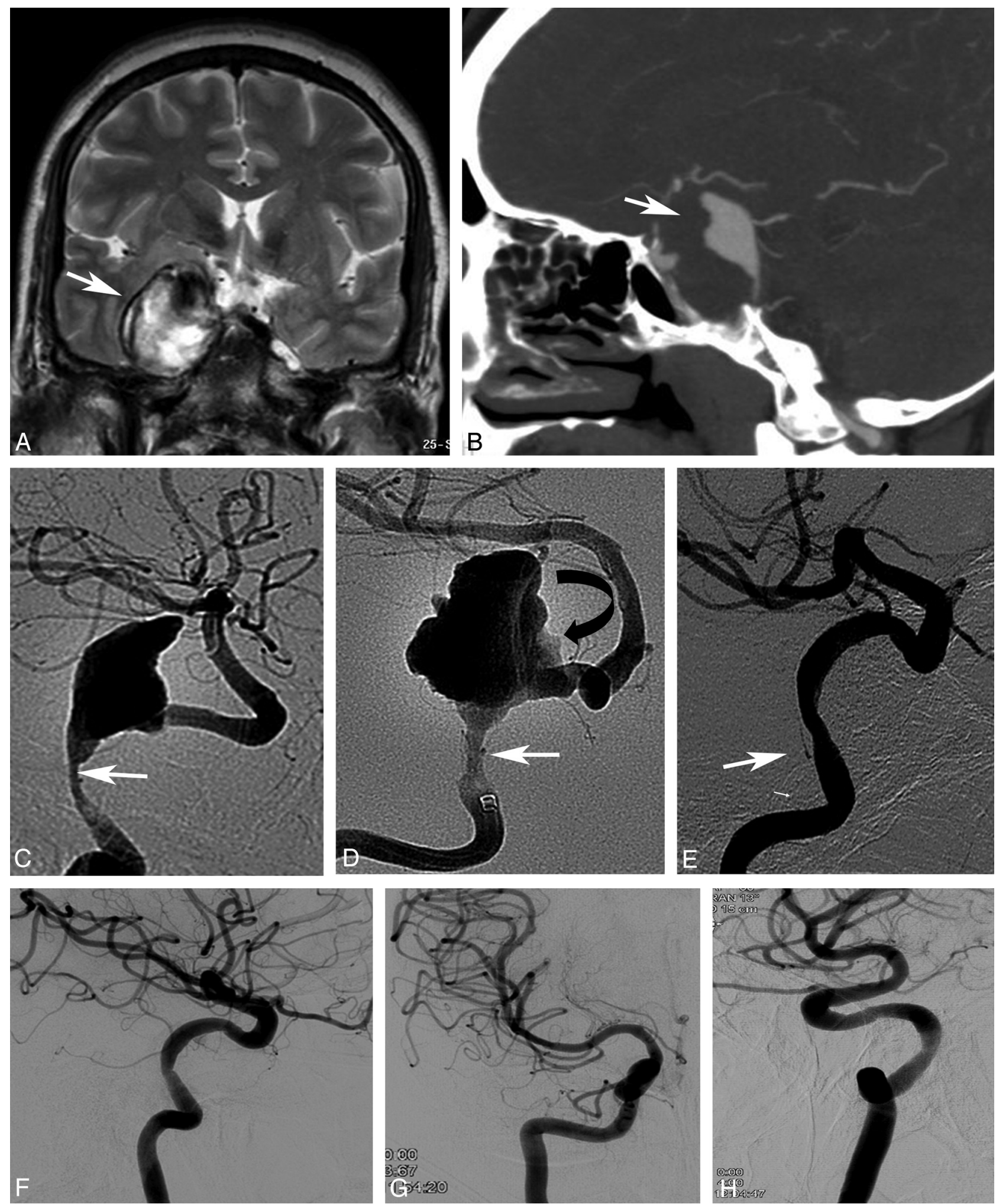

FIG 1. Coronal T2-weighted MRI (A) and sagittal contrast CT (B), in a young female with a giant, partially thrombosed dissecting aneurysm of the right internal carotid artery (arrows). Lateral (C) and frontal DSA images (D) show the site of dissection (arrow) and irregular aneurysmal lumen corresponding to intra-aneurysmal clot (curved arrow). Seven-month follow-up angiography after placement of a Surpass FD (E) shows complete aneurysm occlusion with mild narrowing at the level of dissection (arrow). Twelve-month follow-up in lateral, frontal, and oblique views $(F-H)$ shows stable aneurysm occlusion with no major remaining stenosis. Note the nearly isolated right hemisphere due to a small right Al artery.

Wire perforation was encountered in 2 patients, including 1 patient with a large dissecting fusiform aneurysm of the pericallosal artery. All 5 patients showed various degrees of improvement of their neurologic deficits and functional status (mRS) at their latest clinical follow-up.

Of the patients with anterior circulation aneurysms who had 

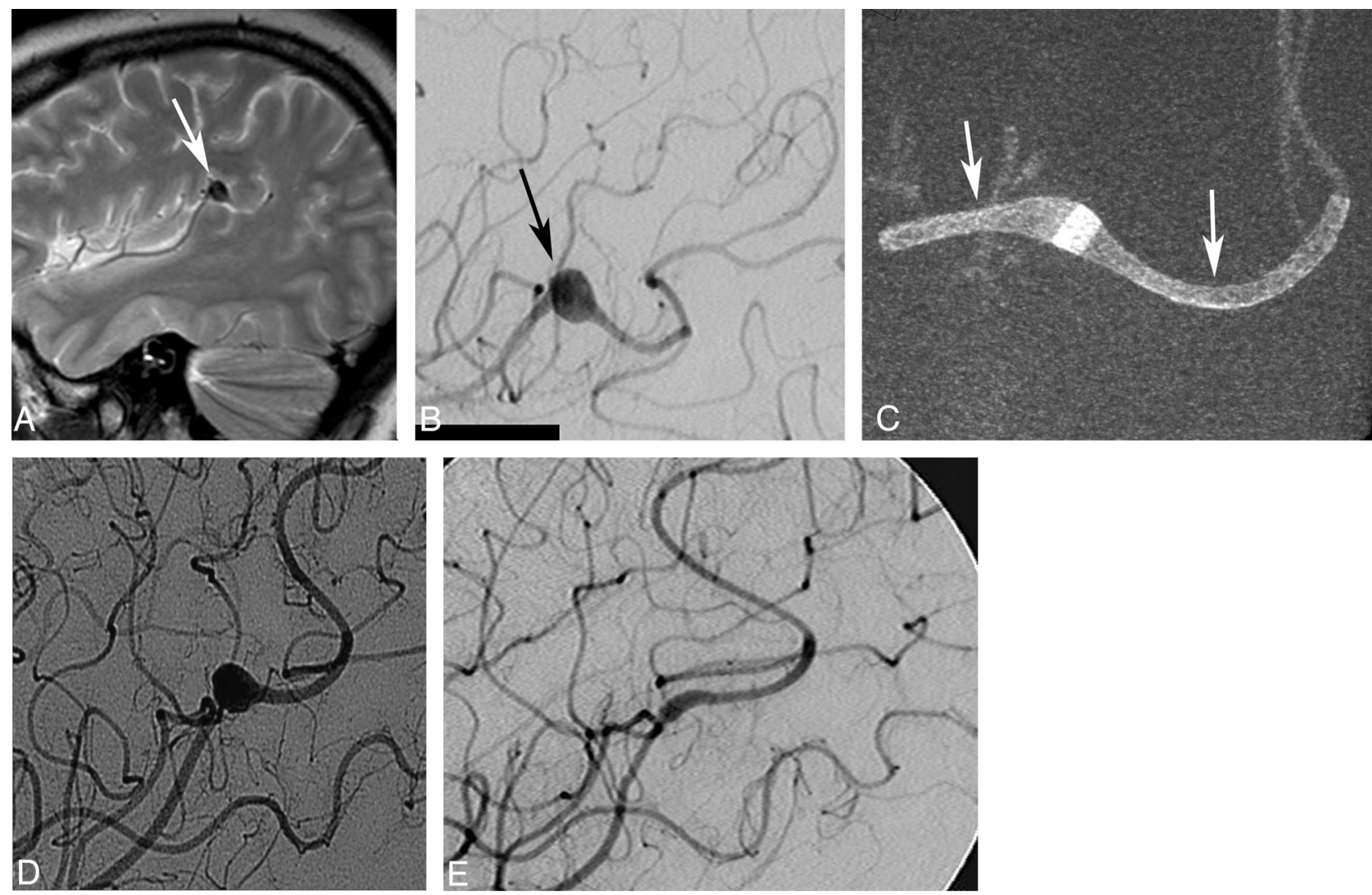

FIG 2. A, A young female patient with a mycotic aneurysm (arrow) of the left middle cerebral artery intractable to antibiotic treatment. $B$, The fusiform aneurysm (arrow) measures $8 \times 7 \mathrm{~mm}$ and originates from the angular artery. The patient failed a balloon-test occlusion of the angular artery and was considered for flow-diverter treatment. Conebeam CT (C) shows the aneurysm treated with 2 overlapping Surpass FDs $(2 \times 15$ and $2 \times 10 \mathrm{~mm}$, arrows). Follow-up angiogram $(D)$ shows excellent parent artery flow and filling of the aneurysm. Six-month follow-up angiogram (E) shows a complete aneurysm occlusion. Note that a second FD device had to be implanted because the first one did not cover the entire lesion. This was related to poor visibility of the first generation of the FD, which did not have platinum markers, which were added to the second generation of the implant.
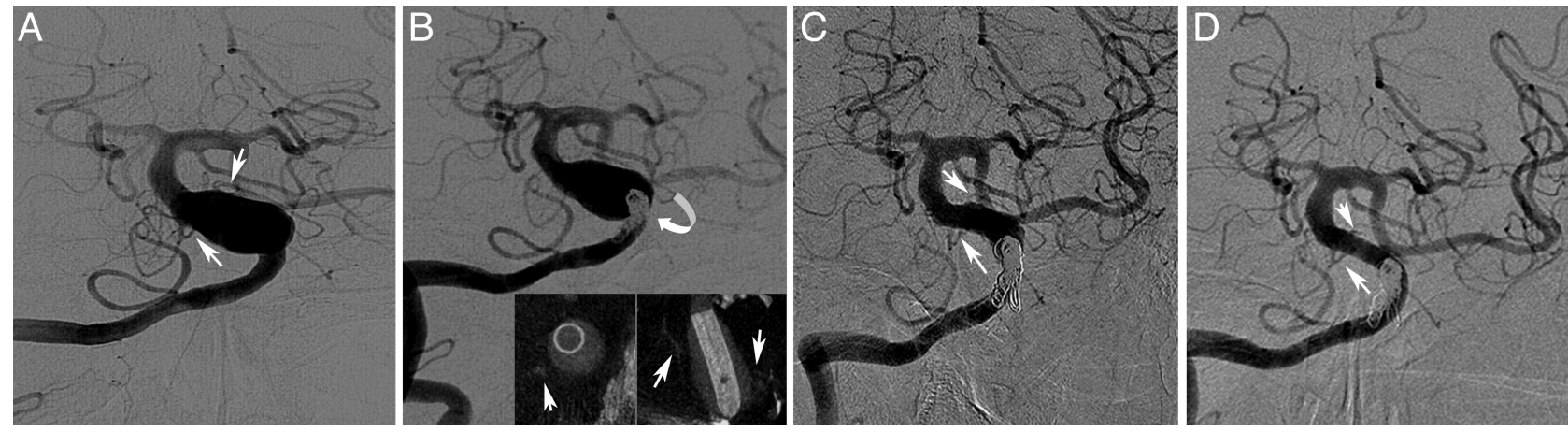

FIG 3. A, A male patient with a $20 \times 30 \mathrm{~mm}$ symptomatic fusiform basilar trunk aneurysm involving both anterior inferior cerebellar arteries (arrows) and the vertebrobasilar junction. Coil occlusion (B) of the left vertebral artery to prevent "endoleak" (curved arrow) and placement of a single $5 \times 50 \mathrm{~mm}$ Surpass FD with patency of anterior inferior cerebellar arteries (conebeam angio-CT; insert, small arrows). C and D, Progressive thrombosis of the aneurysm with remodeling of the basilar trunk and preservation of both anterior inferior cerebellar arteries (small arrows) at 3- and 14-month follow-up angiography. Note the previously occluded left internal carotid artery with a secondary enlarged left posterior communicating artery feeding the middle cerebral artery. The distal basilar trunk and left P1 segment not covered by the FD remain enlarged.

transient neurologic deficits during the clinical follow-up period, 1 experienced parenchymal bleeding ipsilateral to the treated area. The patient presented with a frontal lobe hematoma 1 day after treatment of a giant carotid cavernous aneurysm that required decompressive surgery; after initial headache, the patient remains asymptomatic following surgery.
Posterior Circulation. During the clinical follow-up period, 2 of 27 patients $(7.4 \%)$ treated for posterior circulation aneurysms died, both of whom presented with symptomatic fusiform aneurysms affecting the entire basilar trunk and proximal segment of the posterior cerebral arteries.

Procedure-related morbidity was encountered in 2 patients 


\begin{tabular}{|c|c|}
\hline \multicolumn{2}{|l|}{ FD implantation } \\
\hline Attempted treatment (patients/aneurysms) & $165 / 190$ \\
\hline $\begin{array}{l}\text { FD implantation at target site (patients/ } \\
\text { aneurysms) }\end{array}$ & $161(97.5 \%) / 186(98 \%)$ \\
\hline Average No. of devices used per patient & 1.2 \\
\hline Average No. of devices used per aneurysm & 1.05 \\
\hline Average procedure length (min) & 79.8 \\
\hline \multicolumn{2}{|l|}{ Technical complications } \\
\hline $\begin{array}{l}\text { Incorrect placement with partial aneurysm } \\
\text { coverage }\end{array}$ & $4(2.1 \%)$ \\
\hline Guidewire perforation & $5(3.1 \%)$ \\
\hline $\begin{array}{l}\text { Intraoperative thrombus formation } \\
\text { (asymptomatic/symptomatic) }\end{array}$ & $6(3.7 \%) / 0$ \\
\hline Vasospasm & $6(3.7 \%)$ \\
\hline \multicolumn{2}{|l|}{ Serious adverse events } \\
\hline Any death during the follow-up & $7(4.3 \%)$ \\
\hline Patients available for follow-up & $150(93.2 \%)$ \\
\hline Patients lost to or refusing follow-up & $11(6.8 \%)$ \\
\hline $\begin{array}{l}\text { Primary end point (any stroke and } \\
\text { neurologic death) }\end{array}$ & $18(12 \%)$ \\
\hline Permanent morbidity & $9(6.0 \%)$ \\
\hline Procedure-related mortality & $4(2.7 \%)$ \\
\hline
\end{tabular}

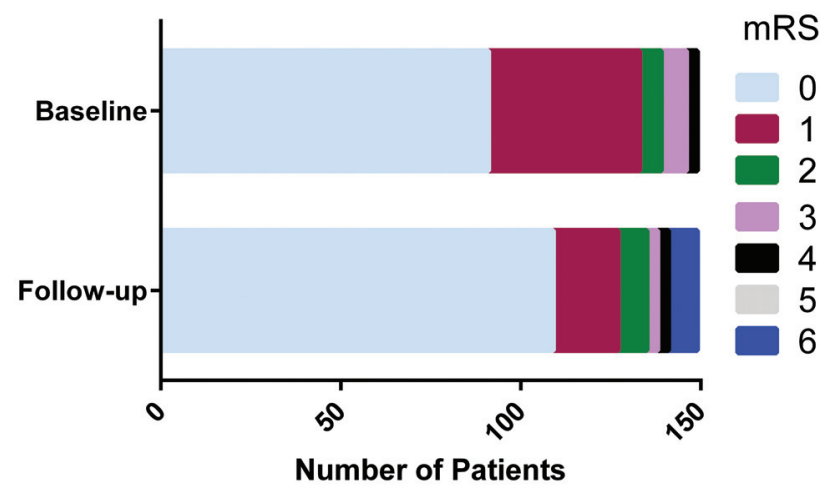

FIG 4. Modified Rankin Scale score at presentation and follow-up in 150 patients. A Wilcoxon matched-pairs signed rank test $(P=.55)$ indicates no significant change in patient neurologic outcomes.

(7.4\%). One patient was treated for a $19-\mathrm{mm}$ symptomatic basilar apex-superior cerebellar artery aneurysm. After initially having an excellent recovery, 3 weeks following the EVT, the patient had a midbrain and brain stem stroke from a suspected perforator occlusion, resulting in right-sided hemiplegia. The other patient, who was treated for a large basilar trunk aneurysm, had pre-existing severe intracranial atherosclerotic disease and a history of posterior circulation stroke. Five months following the EVT and discontinuation of dual antiplatelet therapy, the patient presented with basilar thrombosis that was treated with IV thrombolysis. Despite successful revascularization, the patient retained homonymous hemianopia and diplopia at left lateral gaze.

The only confirmed perianeurysmal bleed was in a posterior circulation aneurysm observed several weeks after the EVT in a patient with a growing large symptomatic (occipital pain and ataxia) dissecting vertebral artery-posterior inferior cerebellar artery aneurysm that, at follow-up angiography, was completely obliterated. The patient's preprocedural symptoms have resolved completely, and the patient remains asymptom- atic 24 months following the procedure. In the posterior circulation, 1 patient presented with a parenchymal superior vermian bleed 6 days after placement of the FD for a dissecting intracranial segment of the vertebral artery. The patient presented with mild dizziness and returned to baseline at 30-day follow-up.

\section{Efficacy}

Of 186 aneurysms that received an FD, 158 (86.8\%) were available for a DSA follow-up (median, 6 months; range, 1-38 months). Additionally, 2 patients had a 6-month follow-up MRA that was not assessed because the protocol required DSA. Complete occlusion $(100 \%)$ was seen in $118(75 \%)$ aneurysms of all locations (Table 3). Near-complete or complete occlusion (95\%-100\%) was observed in $127(80 \%)$ aneurysms. A subgroup analysis showed complete occlusion in $78.6 \%$ of anterior circulation aneurysms below the ICA terminus, while $65.8 \%$ and $72.7 \%$ of aneurysms located in the anterior circulation distal to the circle of Willis and the posterior circulation, respectively, were occluded (Table 3). Starting at 3-month follow-up, a progressive thrombosis of the aneurysm was seen, with most of the aneurysms obliterated between 6 and 12 months after FD placement (Fig 5). Of the 5 aneurysms that were previously treated with stent-assisted coil embolization, 3 did not show complete occlusion at 6-month follow-up angiography and were successfully re-treated with a second FD. Of the 4 aneurysms with incomplete neck coverage at EVT, 2 showed incomplete occlusion at follow-up.

At follow-up, significant stenosis ( $\geq 50 \%$ ) within the FD was seen in 8 patients (5\%), who remained asymptomatic. The area of stenosis was associated with device malapposition that had not been addressed with balloon postdilation at the time of placement in all 8 patients. Another patient ceased dual antiplatelet therapy 4 months following treatment due to head trauma, and subsequently the implant was occluded with worsening of pre-existing aphasia.

\section{DISCUSSION}

\section{Specific Features of the FD}

The single-layer braided FD used in this clinical study was engineered on the basis of previous extensive experimental hydrodynamic studies. ${ }^{5,6,8,9}$ In vitro and computational fluid dynamic research showed that FDs create impedance to the flow at the neck of the aneurysm and reduce the hydrodynamic circulation inside the aneurysm pouch. ${ }^{10}$ This outcome is achieved by the attenuation of the peak and mean kinetic energy of the blood entering the aneurysm with each pulse cycle. Subsequent in vivo experiments confirmed that the flow reduction led to progressive aneurysm thrombosis and, ultimately, endothelialization of the FD surface and the aneurysm neck. ${ }^{6}$ As detailed previously, this result required an FD porosity of optimally $70 \%$, which was sufficient for an intra-aneurysmal flow reduction while maintaining flow through vital perforators. ${ }^{5,8-11}$ With the increase in diameter and to maintain biomechanical stability within the parent artery, the number of wires of an FD had to be increased. Ensuring the desired porosity required a reduction of FD wire thickness. These changes resulted in a consistent mesh density and 


\begin{tabular}{|c|c|c|c|c|c|}
\hline \multirow[b]{3}{*}{ Aneurysm Location } & \multicolumn{5}{|c|}{ Aneurysm Occlusion } \\
\hline & \multicolumn{4}{|c|}{ Occlusion Rate ${ }^{\mathrm{b}}(\%)$} & \multirow[b]{2}{*}{ Total } \\
\hline & $<50$ & $50-95$ & $>95$ & 100 & \\
\hline Anterior circulation (ICA) & $6(6.1 \%)$ & $11(11.2 \%)$ & $4(4.1 \%)$ & $77(78.6 \%)$ & 98 \\
\hline Petrocavernous & & 1 & & 3 & 4 \\
\hline Cavernous & & 2 & 2 & 12 & 16 \\
\hline Carotid cave & 1 & & & 3 & 4 \\
\hline Superior hypophyseal & 1 & & & 3 & 4 \\
\hline Paraophthalmic & 2 & 2 & & 24 & 28 \\
\hline Paraclinoid & & & & 3 & 3 \\
\hline Supraclinoid & 1 & 1 & & 3 & 5 \\
\hline Posterior communicating artery & 1 & 4 & 2 & 24 & 31 \\
\hline Anterior choroidal artery & & 1 & & 2 & 3 \\
\hline Anterior circulation distal to circle of Willis & $2(5.3 \%)$ & $9(23.7 \%)$ & $2(5.3 \%)$ & $25(65.8 \%)$ & 38 \\
\hline ICA terminus & 1 & 1 & 1 & 2 & 5 \\
\hline Anterior cerebral artery (including AcomA) & & 1 & 1 & 7 & 9 \\
\hline Middle cerebral artery & 1 & 7 & & 16 & 24 \\
\hline Posterior circulation & $1(4.5 \%)$ & $2(9.1 \%)$ & $3(13.6 \%)$ & $16(72.7 \%)$ & 22 \\
\hline VA and VB junction & & 1 & & 7 & 8 \\
\hline Posterior inferior cerebellar artery & & 1 & 2 & 2 & 5 \\
\hline Basilar trunk & 1 & & 1 & 4 & 6 \\
\hline Posterior cerebral artery & & & & 3 & 3 \\
\hline Total & $9(6 \%)$ & $22(13 \%)$ & $9(6 \%)$ & $118(75 \%)$ & 158 \\
\hline
\end{tabular}

Note:-AcomA indicates anterior communicating artery; VA, vertebral artery; VB, vertebrobasilar.

${ }^{a}$ Digital subtraction angiography follow-up was available in 158 aneurysms (86.8\%).

${ }^{b}$ Occlusion rates at the latest follow-up are based on aneurysm volume calculated on pre-and posttreatment digital subtraction angiograms.

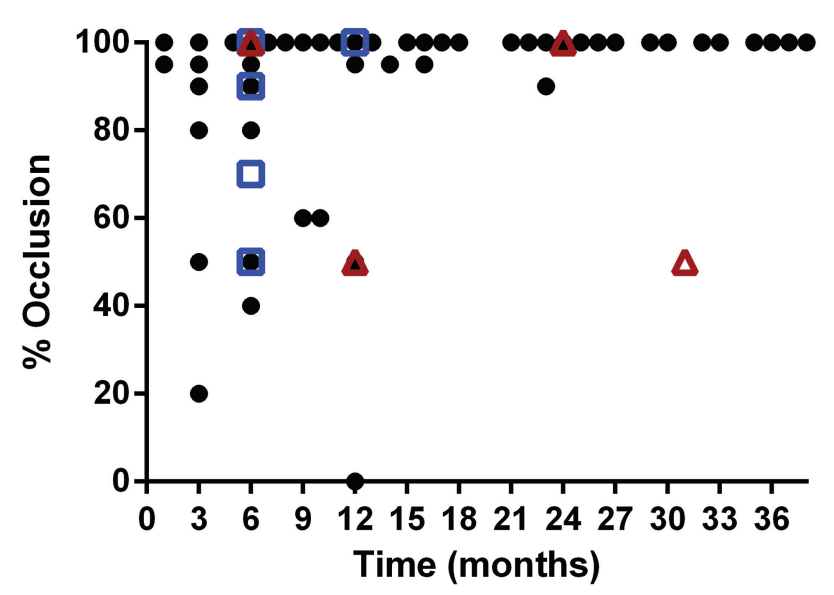

- FD

$\Delta$ FD - incomplete aneurysm coverage FD over previous stent

FIG 5. Percentage of occlusion of the aneurysm as a function of time from implant. Incomplete coverage of the aneurysm by the FD and FD implantation over a prior stent are noted by red triangles and blue squares, respectively.

cell shape of the implant, enabling an effective flow reduction at various parent vessel diameters. The resulting braid angle also reduced the foreshortening of the device and enhanced a precise placement.

"Herniation" of the FD into the aneurysm alters the ultrastructure of the device (cell shape and porosity) and changes the effect on flow diversion, as recently reported with other nitinolbased implants. ${ }^{12}$ The braid angle also eliminates the potential risk of creating pockets of large openings between the struts, es- pecially in aneurysms located in tight bends. Changes of FD configuration and mesh porosity once implanted into the artery may create an inconsistent pattern of intra-aneurysmal flow and insufficient resistance to the flow at the aneurysm neck that necessitates the use of multiple FDs. The central goal of the aforementioned engineering studies was to create a single optimized FD for efficacious treatment across a broad range of intracranial aneurysms. Preliminary data of the Surpass FD at a single center reinforced these experimental results, demonstrating an occlusion rate of $94 \%$ at 6 months in 31 aneurysms. ${ }^{7}$ The reported occlusion rate in this multicenter study is lower; however, this was anticipated because the prior report was from a single center at a high-volume site that has extensive experience with this device.

The clinical data presented herein reinforce the experimental findings. ${ }^{6}$ The use of a single device (compared with a median of 3 used in the Pipeline Embolization Device for Uncoilable or Failed Aneurysms [PUFS] trial ${ }^{13}$ ) led to a comparable high rate of progressive aneurysm occlusion. Moreover, the average procedural time in this study was 79.8 minutes compared with 124 minutes in the PUFS trial. ${ }^{13}$ Similar to our observations, the PUFS study confirmed the progressive nature of aneurysm occlusion: At 6 months, $73.6 \%$ of aneurysms were obliterated, and at 12 months, $86.8 \%$ were thrombosed. As in our series, a high complete occlusion rate was observed in large or giant aneurysms. Specifically, there were 22 aneurysms of $>10 \mathrm{~mm}$ located in the ICA below the circle of Willis having no underlying prior stent, with follow-up at a minimum of 6 months. In this small cohort, 18 $(81.8 \%)$ were completely occluded at 6-month follow-up and 3 $(13.6 \%)$ had a small neck remnant ( $>95 \%$ occluded). One aneurysm $(4.5 \%)$ was $>90 \%$ occluded at 6 -month follow-up angiography. Several recently published meta-analyses of EVT in $>1000$ intracranial aneurysms with FDs showed a complete 
occlusion rate as high as $76 \% .{ }^{14,15}$ A retrospective analysis of the Italian multicenter experience with flow-diverter devices for intracranial aneurysms that included the Pipeline Embolization Device (Covidien) and Silk stent (Balt Extrusion, Montmorency, France) showed an $85 \%$ aneurysm occlusion at 3 months. ${ }^{16}$

\section{Patient Selection and Angiographic Occlusion}

Caution should be exercised when comparing occlusion rates between different FDs because patient selection and trial design may affect outcome. In our series, only $14 \%$ of the patients presented with extradural aneurysms, whereas in the PUFS trial, a large subgroup had petrous and cavernous aneurysms (44.4\%). ${ }^{13}$ Thus, the risk of spontaneous aneurysm rupture before complete aneurysm thrombosis during the observation period differs. These preliminary data are encouraging, and the FD achieved a complete $(100 \%)$ or near-complete ( $>95 \%$ ) occlusion at follow-up in $81 \%$ of the treated aneurysms. To render a true assessment of the FD, we enrolled patients with aneurysms originating at all locations in the intracranial circulation, including more challenging aneurysms such as those found at the MCA bifurcation and anterior communicating artery. Like other studies, a variety of aneurysms with complex angiographic appearances (multiple adjacent aneurysms with dysplastic arteries, dissecting and blister aneurysms) was captured in our series and most likely does not reflect the same underlying disease or disease stage. Lanzino et $\mathrm{al}^{17}$ showed, in a matched-pair analysis, that FD treatment in 22 paraclinoid aneurysms achieved a $77.3 \%$ complete occlusion versus $45.4 \%$ with standard EVT, including stent-assisted coiling with fewer intra- and postoperative complications for the FD arm.

\section{Bleeding and Thromboembolic Complications}

Previously published studies and case series have reported morbidity and mortality as high as $9 \%$ and $6 \%$, respectively. ${ }^{13,18-22}$ Morbidity and mortality with the Silk device (Balt Extrusion) are reported to be slightly higher, with $\leq 15 \%$ and $8 \%$, respectively. ${ }^{23-25}$ Two recently published meta-analyses on FD treatment in up to 1451 patients with 1654 aneurysms showed a not-negligible procedure-related morbidity and mortality of $5 \%-10 \%$ and $4 \%$, respectively. ${ }^{14,15}$ The authors found an occurrence of postoperative SAH, intraparenchymal hemorrhage, and perforator infarctions of 3\% in each category. The rates of $\mathrm{SAH}$, intraparenchymal hemorrhage, and ischemic stroke at $\leq 30$ days were $3 \%, 3 \%$, and $5 \%$, respectively. $\mathrm{SAH}$, intraparenchymal hemorrhage, and ischemic stroke at $>30$ days occurred in $2 \%, 2 \%$, and $3 \%$ of the patients, respectively. Perforator occlusions were significantly higher in the posterior circulation compared with aneurysms located in the anterior circulation. Ischemic stroke was encountered in $6 \%$ of patients. ${ }^{14}$ Our results are comparable with those in other studies; any permanent neurologic morbidity and mortality were seen in $6 \%$ and $2.7 \%$, respectively. In our series, we did not encounter SAH after 7 days following FD placement. In a preliminary study of this FD in 39 patients, there was a lower permanent morbidity rate of $4 \%$ and no mortality. ${ }^{7}$ This larger, multicenter study showed a slight increase in morbidity. The increase in mortality is likely attribut- able to the study design and the inclusion of complex aneurysms, particularly in the posterior circulation.

Our experience with the FD in the posterior circulation has been comparable with that in the anterior circulation with the exception of fusiform dolichoectatic aneurysms of the entire basilar trunk. Two of 4 patients treated for an entire basilar trunk aneurysm died from FD treatment. Siddiqui et $\mathrm{al}^{26}$ reported 7 patients with large or giant fusiform vertebrobasilar aneurysms treated with the Silk or Pipeline Embolization Device, 4 of whom died; 3 were left with severe disability following the procedure. The use of a single, long implant, compared with the need for telescoping the Pipeline Embolization Device with the potential risk of perforator occlusion, may mitigate periprocedural morbidity.

Although stent-assisted coil embolization has not been the subject of randomized clinical trials, this technology has been available for cerebrovascular aneurysm treatment for more than a decade. Consequently, numerous studies have been published regarding the safety and efficacy of the technique. In a comprehensive review by Shapiro et al, ${ }^{27}$ stent-assisted coil-embolization complications and mortality were seen in 19\% and 2.1\%, respectively. Although most aneurysms included in this analysis were unruptured, acutely ruptured aneurysms were also included. As with all new technology, there was a documented learning curve, with complication rates being higher in the first 10 patients treated. Most complications (10\%) were thromboembolic. If we restricted the analysis to unruptured or nonacutely ruptured aneurysms, the rates of morbidity and mortality varied between $3.8 \%-8.3 \%$ and $0 \%-3.9 \%$, respectively. ${ }^{28-34}$ The data presented in our study show a safety profile comparable with that of stentassisted coil embolization.

\section{Study Limitations}

Assessment at clinical follow-up and serious adverse events were self-adjudicated by physicians' participating sites. Another major limitation of the data collected is the nonrandomized nature of the study and lack of a control arm. Patients with ruptured aneurysms were not included in the acute stage but were treated electively if other treatments were not an option. Finally, most aneurysms included in this trial are $<10 \mathrm{~mm}$. Presently, the FD studied herein is undergoing the Surpass intraCranial aneurysm EmbolizatioN system Trial (SCENT), which is a multicenter, prospective single-arm trial designed to assess the safety and efficacy of the device for the treatment of large or giant wideneck aneurysms. On completion of this trial, more data will be available on the ability of the device to treat large and giant aneurysms.

\section{CONCLUSIONS}

Clinical data demonstrate an acceptable safety profile compared with other FD technology and stent-assisted coil embolization. High occlusion rates were observed for a wide range of intracranial aneurysms of the anterior and posterior circulation without the need for coiling and with the use of a single FD implant. The observed progressive occlusion requires long-term follow-up studies. The treatment of a subset of fusiform aneurysms affecting the entire basilar artery remains challenging. 
Disclosures: Ajay K. Wakhloo-UNRELATED: Consultancy: Stryker Neurovascular; Employment: Surpass Medical; Grants/Grants Pending: Philips Healthcare*; Payment for Lectures (including service on Speakers Bureaus): Harvard Medical School, Miami Baptist Health; Stock/Stock Options: Surpass Medical. Pedro Lylyk—UNRELATED: Board Membership: Covidien, Comments: no monetary compensation; Consultancy: Covidien, Surpass, Cardiatis, MicroVention, Phoenix; Payment for Lectures (including service on Speakers Bureaus): Covidien; Stock/Stock Options: Surpass; Travel/Accommodations/Meeting Expenses Unrelated to Activities Listed: Covidien, Cardiatis, Sequent, MicroVention. Joost de Vries_UNRELATED: Consultancy: Stryker Neurovascular; Grants/Grants Pending: Stryker Neurovascular, ${ }^{\star}$ Covidien, ${ }^{*}$ Johnson \& Johnson*; Stock/Stock Options: Stryker Neurovascular; Travel/Accommodations/Meeting Expenses Unrelated to Activities Listed: Stryker Neurovascular. Christian Taschner-UNRELATED: Consultancy: Stryker Neurovascular; Grants/ Grants Pending: MicroVention,* Acandis.* Istvan Szikora-UNRELATED: Consultancy: Stryker Neurovascular, Covidien; Payment for Lectures (including service on Speakers Bureaus): Stryker Neurovascular, Covidien. Laurent Pierot-UNRELATED: Consultancy: Stryker. Nobuyuki Sakai-UNRELATED: Consultancy: Stryker, Terumo/MicroVention, Codman, Covidien; Payment for Lectures (including service on Speakers Bureaus): Stryker, Terumo/MicroVention, Codman, Covidien, Asahi INTECC, Medtronic. Nader Sourour-UNRELATED: Consultancy: Covidien, Penumbra, Stryker; Travel/Accommodations/Meeting Expenses Unrelated to Activities Listed: Surpass, Stryker, Comments: training. lan Rennie-UNELATED: Employment: proctoring agreement with Stryker Neurovascular, Comments: agreement in place recently (no work done as yet and no payments made). Matthew J. Gounis-UNRELATED: Consultancy: Codman Neurovascular, Surpass (Contract Research Organization), Surpass Medical, Stryker Neurovascular, Comments: fee-per-hour consulting; Grants/Grants Pending: Philips Healthcare, ${ }^{*}$ National Institutes of Health, ${ }^{*}$ Covidien/ev3, ${ }^{*}$ Silk Road, ${ }^{*}$ Lazarus Effect, ${ }^{*}$ Wyss Institute, ${ }^{*}$ Fraunhofer Institute, ${ }^{*}$ Stryker Neurovascular.* Marc W. Litzenberg-UNRELATED: Employment: Stryker Neurovascular. Francis Turjman-UNRELATED: Consultancy: Covidien, Codman, Balt; Grants/Grants Pending: Covidien; Payment for Lectures (including service on Speakers Bureaus): Codman, Covidien; Payment for Development of Educational Presentations: Codman; Travel/Accommodations/Meeting Expenses Unrelated to Activities Listed: Stryker, Covidien, Codman. Patrick Brouwer-UNRELATED: Board Membership: Netherlands Neurovascular Association (nonpaid membership); Consultancy: Codman, DePuy Synthes*; Payment for Lectures (including service on Speakers Bureaus): Balt Extrusion, ${ }^{*}$ Toshiba.* Alain Bonafé-UNRELATED: Consultancy: Stryker. Edoardo Boccardi-UNRELATED: Board Membership: Stryker, Covidien, MicroVention; Consultancy: Stryker, Covidien, MicroVention; Payment for Lectures (including service on Speakers Bureaus): MicroVention; Travel/Accommodations/Meeting Expenses Unrelated to Activities Listed: Stryker. *Money paid to the institution.

\section{REFERENCES}

1. Wakhloo AK, Schellhammer F, de Vries J, et al. Coated and noncoated stents for vessel reconstruction and treatment of aneurysms and AV fistulas: an experimental study (abstract). Neuroradiology 1992;34(suppl):24

2. Wakhloo AK, Schellhammer F, Vries JD, et al. Self-expanding and balloon-expandable stents in the treatment of carotid aneurysms: an experimental study in a canine model. AJNR Am J Neuroradiol 1994;15:493-502

3. Turjman F, Acevedo G, Moll T, et al. Treatment of experimental carotid aneurysms by endoprosthesis implantation: preliminary report. Neurol Res 1993;15:181-84

4. Geremia G, Haklin M, Brennecke L. Embolization of experimentally created aneurysms with intravascular stent devices. AJNR Am J Neuroradiol 1994;15:1223-31

5. Seong J, Wakhloo AK, Lieber BB. In vitro evaluation of flow diverters in an elastase-induced saccular aneurysm model in rabbit. J Biomech Eng 2007;129:863-72

6. Sadasivan C, Cesar L, Seong J, et al. An original flow diversion device for the treatment of intracranial aneurysms: evaluation in the rabbit elastase-induced model. Stroke 2009;40:952-58

7. De Vries J, Boogaarts J, Van Norden A, et al. New generation of flow diverter (Surpass) for unruptured intracranial aneurysms: a prospective single-center study in 37 patients. Stroke 2013;44:1567-77

8. Lieber BB, Gounis MJ. The physics of endoluminal stenting in the treatment of cerebrovascular aneurysms. Neurol Res 2002;24(suppl 1):S33-42

9. Lieber BB, Sadasivan C. Endoluminal scaffolds for vascular recon- struction and exclusion of aneurysms from the cerebral circulation. Stroke 2010;41:S21-25

10. Aenis M, Stancampiano AP, Wakhloo AK, et al. Modeling of flow in a straight stented and non-stented sidewall aneurysm model. $J$ Biomech Eng 1997;119:206-12

11. Kallmes DF, Ding YH, Dai D, et al. A new endoluminal, flow-disrupting device for treatment of saccular aneurysms. Stroke 2007;38:2346-52

12. Raymond J, Darsaut TE, Makoyeva A, et al. Endovascular treatment with flow diverters may fail to occlude experimental bifurcation aneurysms. Neuroradiology 2013;55:1355-63

13. Becske T, Kallmes DF, Saatci I, et al. Pipeline for uncoilable or failed aneurysms: results from a multicenter clinical trial. Radiology 2013;267:858-68

14. Brinjikji W, Murad MH, Lanzino G, et al. Endovascular treatment of intracranial aneurysms with flow diverters: a meta-analysis. Stroke 2013;44:442-47

15. Arrese I, Sarabia R, Pintado R, et al. Flow-diverter devices for intracranial aneurysms: systematic review and meta-analysis. Neurosurgery 2013;73:193-99, discussion 199-200

16. Briganti F, Napoli M, Tortora F, et al. Italian multicenter experience with flow-diverter devices for intracranial unruptured aneurysm treatment with periprocedural complications: a retrospective data analysis. Neuroradiology 2012;54:1145-52

17. Lanzino G, Crobeddu E, Cloft HJ, et al. Efficacy and safety of flow diversion for paraclinoid aneurysms: a matched-pair analysis compared with standard endovascular approaches. AJNR Am J Neuroradiol 2012;33:2158-61

18. Lylyk P, Miranda C, Ceratto R, et al. Curative endovascular reconstruction of cerebral aneurysms with the Pipeline embolization device: the Buenos Aires experience. Neurosurgery 2009;64:632-42

19. Fischer S, Vajda Z, Aguilar Perez M, et al. Pipeline embolization device (PED) for neurovascular reconstruction: initial experience in the treatment of 101 intracranial aneurysms and dissections. Neuroradiology 2012;54:369-82

20. Szikora I, Berentei Z, Kulcsar Z, et al. Treatment of intracranial aneurysms by functional reconstruction of the parent artery: the Budapest experience with the Pipeline embolization device. AJNR Am J Neuroradiol 2010;31:1139-47

21. McAuliffe W, Wycoco V, Rice H, et al. Immediate and midterm results following treatment of unruptured intracranial aneurysms with the Pipeline embolization device. AJNR Am J Neuroradiol 2012;33:164-70

22. O'Kelly CJ, Spears J, Chow M, et al. Canadian experience with the Pipeline embolization device for repair of unruptured intracranial aneurysms. AJNR Am J Neuroradiol 2013;34:381-87

23. Byrne JV, Beltechi R, Yarnold JA, et al. Early experience in the treatment of intra-cranial aneurysms by endovascular flow diversion: a multicentre prospective study. PLoS One 2010;5:e12492

24. Velioglu M, Kizilkilic O, Selcuk $\mathrm{H}$, et al. Early and midterm results of complex cerebral aneurysms treated with Silk stent. Neuroradiology 2012;54:1355-65

25. Lubicz B, Collignon L, Raphaeli G, et al. Flow-diverter stent for the endovascular treatment of intracranial aneurysms: a prospective study in 29 patients with 34 aneurysms. Stroke 2010;41:2247-53

26. Siddiqui AH, Abla AA, Kan P, et al. Panacea or problem: flow diverters in the treatment of symptomatic large or giant fusiform vertebrobasilar aneurysms. J Neurosurg 2012;116:1258-66

27. Shapiro M, Becske T, Sahlein D, et al. Stent-supported aneurysm coiling: a literature survey of treatment and follow-up. AJNR Am J Neuroradiol 2012;33:159-63

28. Standhardt H, Boecher-Schwarz H, Gruber A, et al. Endovascular treatment of unruptured intracranial aneurysms with Guglielmi detachable coils: short- and long-term results of a single-centre series. Stroke 2008;39:899-904

29. Santillan A, Greenberg E, Patsalides A, et al. Long-term clinical and angiographic results of Neuroform stent-assisted coil embolization 
in wide-necked intracranial aneurysms. Neurosurgery 2012;70: 1232-37, discussion 1237

30. Wakhloo AK, Linfante I, Silva CF, et al. Closed-cell stent for coil embolization of intracranial aneurysms: clinical and angiographic results. AJNR Am J Neuroradiol 2012;33:1651-56

31. Starke RM, Durst CR, Evans A, et al. Endovascular treatment of unruptured wide-necked intracranial aneurysms: comparison of dual microcatheter technique and stent-assisted coil embolization. J Neurointerv Surg 2014 Mar 25. [Epub ahead of print]
32. Wang K, Sun Y, Li AM. Peri-procedural morbidity and mortality associated with stent-assisted coiling for intracranial aneurysms. Interv Neuroradiol 2013;19:43-48

33. Hwang SK, Hwang G, Bang JS, et al. Endovascular Enterprise stentassisted coil embolization for wide-necked unruptured intracranial aneurysms. J Clin Neurosci 2013;20:1276-79

34. Kim SR, Vora N, Jovin TG, et al. Anatomic results and complications of stent-assisted coil embolization of intracranial aneurysms. Interv Neuroradiol 2008;14:267-84 